\title{
Electrical stimulation of the retina: aspects arising from retinal noise
}

\begin{abstract}
Various impacts of the spontaneous neuronal noise on visual processing in the brain and the retina are extensively studying and discussing. Highly variable behavior is characteristic of healthy physiological systems, but dynamics of functional activity is simplifying in pathology and became either very ordered or characterized by entirely uncorrelated random oscillations. It has been demonstrated by several research groups that in hereditary retinal degeneration, sensory deafferentation arising from the loss of photoreceptors increases the spontaneous activity throughout the visual system and leads an aberrant rhythmic activity of retinal ganglion cells. In patients blind due to retinitis pigmentosa, retinal prosthetic devices are currently applying to obtain visual sensations induced by the electrical pulses. The right choice of the parameters of electrical stimuli is of great importance for achieving reliable responses from the RGCs and transmittance of encoded visual information to the brain. The temporal parameters of stimulation are supposed to be crucial to provide the further innovation development of such approach. We hypothesize that the periodic pathological activity in retinal degeneration not only is a factor that hampers the encoding of information and visual images of more quality. It also can aggravate the impact of deafferentation and play the negative role of in a formation of abnormal synaptic contacts during retinal remodeling contributing to the distortion of the complexity of neural circuits in the retina and the brain in retinal degenerations. We guess that the optical flicker and electrical stimulation therapy using the complex-structured (fractal) signals can be the promising approach providing both tuning the temporal sensitivity of the visual system and activation of the neuronal plasticity throughout the visual pathway. Future strategies of vision restoration apparently must be aimed to avoid the rhythmic activity in retinal circuits and to increase the quality of image representation. Here, we present the arguments that the utilizing the fractal modulation of the stimulating pulses in amplitude or frequency as well as using fractal temporal patterns in the background electrical prestimulation may be one of the prospective ways in future elaboration successful retinal prosthesis.
\end{abstract}

Keywords: electrical stimulation, retinal noise, temporal parameters, retinitis pigmentosa
Volume 8 Issue 2 - 2018

\author{
Zueva Marina V \\ Department of Clinical Physiology of Vision, Moscow Helmholtz \\ Research Institute of Eye Diseases, Russian Federation
}

Correspondence: Zueva Marina Vladimirovna, Prof, Dr. Biol. Sci., Head of the Department of Clinical Physiology of Vision, Moscow Helmholtz Research Institute of Eye Diseases, Ministry of Healthcare of Russia, Str. Sadovaya-Chernogryazskaya 14/19, 105062, Moscow, Russian Federation, Tel +7 9165762359 , Email visionlab@yandex.ru

Received: March 19, 2017 | Published: March 29, 2018
Abbreviations: TCES, transcorneal electrical stimulations; RGC, retinal ganglion cell; LFP, local field potential; RP, retinitis pigmentosa; ARMD, age-related macular degeneration; MNU, N-Methyl-N-nitrosourea

\section{Introduction}

\section{Current issues of minimally invasive and prosthesis electrical stimulation of the retina}

In addition to retinal prosthetic devices aimed to induction electrically-elicited visual sensations in patients blinded due to retinitis pigmentosa (RP) and age-related macular degeneration (ARMD), a wide range of electrical stimulation methods aimed at activation of the retina and the related downstream structures are currently known. Transcutaneous, transorbital and transcorneal electrical stimulations (TCES) are minimally invasive; in animal studies, their usefulness for protection of retinal neurons from traumatic or hereditary degeneration have been observed..$^{1-5}$ TCES and transorbital stimulation therapy was found to have positive effects in patients with RP, glaucoma, traumatic optic neuropathy, and occlusions of retinal artery. ${ }^{6-10}$ Some studies showed that the transpalpebral electrical retinal stimulation therapy could be non-invasively applied in patients with dry- or wet-type agerelated macular degeneration. ${ }^{11,12}$ However, these authors concluded that the method should be treated with caution and randomized controlled studies are needed to test long-term effects.

It is crucial that the beneficial effects of TCES are not limited to retinal neurons and also extend to the cortical activity. ${ }^{13-15}$ Furthermore, the low-intensive whole-eye electrical stimulation in rats with hereditary retinal degeneration having a beneficial effect on visual function gives a particularly significant impact for responses of post-receptoral neurons. ${ }^{16}$

Multiple mechanisms have been proposed underlying the beneficial effects of electrical stimulation (for review see) ) $^{5,15}$ including vasodilatory, neurotrophic, anti-apoptotic, antiexcitotoxic and anti-inflammatory mechanisms. It is assumed that the exact neuroprotective mechanism of the TCES impact might be particular for the specific pathology, and simultaneously multiple mechanisms might give a collective contribution promoting cell survival. For subretinal implants, the neuroprotective potential of electrical stimulation was noted related to increasing production the neurotrophic factors in neural tissues. ${ }^{1}$ Different kinds of electrical stimulation treatment provide the upregulation of neurotrophic factors in the CNS and peripheral nervous system. ${ }^{17-19}$ TCES was found to rescues RGCs by increasing levels of IGF-1 produced by Müller cells. ${ }^{19,20}$ These and many other possible mechanisms underlying the 
effects of minimally invasive electrical stimulation were detailed reviewed in the recent paper. ${ }^{15}$ Sehic A. and coauthors ${ }^{15}$ note that in the clinical trials, effects of electrical stimulation have not yet been proven in relevant ways and need to be demonstrated in future studies. Hereditary degenerative retinal diseases related with the progressive loss of photoreceptors, such as RP, lead to retinal remodeling with retraction of dendrites of rod bipolar and horizontal cells, rewiring of the inner retina circuits but preserve retinal ganglion cells (RGCs) and some other neurons. ${ }^{21-24}$ Over time, $\sim 70 \%$ of RGCs also degenerate, ${ }^{25}$ but a significant fraction of the inner retinal neurons are yet spared. Therefore, retinal prosthetic devices are elaborating for restoring sight in RP and other blinding diseases to electrically stimulate the surviving retinal neurons evoking the RGCs responses that may be transmitted to the brain.

The main targets of electrical stimulation are bipolar cells and RGCs. The electrical pulse depolarizes the cell membrane of a neuron and opens voltage-gated ion channels. In the spiking neurons, such as RGCs, an activation of voltage-sensitive sodium channels leads to the generation of action potentials. Besides, various voltage-gated potassium channels are also expressed after brief electrical pulses in prosthetic stimulation, and the pattern of response was shown to vary depending on the kinetics of activation and inactivation of each subtype of the potassium channel. ${ }^{26}$ There is a reason to hope that the introduction of more advanced stimulation technologies based on the ever-expanding achievements of neuroscience will be able to provide the better quality of image representation encoded in the RGCs responses. Another aspect of this issue is consequences of the massive loss of photoreceptors and retinal remodeling in an animal with retinal degeneration contributing to emergence the pathological background activity of the RGCs with bursts of spikes at the rate of $\sim 5$ to $\sim 10$ $\mathrm{Hz} .{ }^{27-35}$ The prominent signs of the $\mathrm{rd} 1$ and $\mathrm{rd} 10$ retinas compared to the wild-type retina are the arising of spontaneous activity, which is characterized by rhythmic bursts of RGC spikes phase-locked with oscillations of local field potentials (LFPs). Aberrant rhythmic hyperactivity in RGCs has been detected in several strains of mice and rats with hereditary degenerations of the retina. The prevailing theory explaining the arising of this pathological spontaneous rhythm in the photoreceptor-degenerated $\mathrm{rd} 1$ and $\mathrm{rd} 10$ mice retinas relates these oscillations to an intrinsic property of the electrically-coupled network of AII amacrine and ON cone bipolar cell. . $9,30,33,34,36-38^{-3}$

Prospects of the prosthetic stimulation of the retina are dependent on how accurate visual information will be represented in the electrically evoked activity of RGCs transmitted to the brain. Currently, it is not entirely clear how significantly the alterations of the circuitry of degenerating retina and the aberrant rhythmic hyperactivity can hamper the generation of electrically evoked activity. However, the $\mathrm{RGC}$ responses in the retinas of mice with photoreceptor degeneration were shown to encode temporal information on visual input under the stimulation by biphasic electric pulses modulated in amplitude between 2 and $20 \mu \mathrm{A} .{ }^{39}$ It is essential that the temporal profile of the stimulus intensity could be successfully decoded from rd1 RGC spike trains, despite abnormal spontaneous $\sim 10 \mathrm{~Hz}$-rhythms of spikes bursts. Also, the multi-pixel spatiotemporal visual information may be properly decoded from the network RGC activity stimulated by patterned electrical stimulation. ${ }^{40,41}$ The comparing of the RGC evoked activity in the $\mathrm{rd} 10$ and wild-type mice $(\mathrm{C} 57 \mathrm{BL} / 6 \mathrm{~J})$ retinas recorded with a flexible microelectrode array simultaneously with subretinal anodal stimulation show the similar spatiotemporal patterns for the electrically evoked spikes of the RGCs. ${ }^{40}$
However, it is thought that the increased aberrant activity may confound signal processing in the inner retina and increase the background noise passed from retinal ganglion cells (RGCs) to the brain. ${ }^{42}$ Haselier C. and coauthors showed that spontaneous rhythmic activity in the MNU-treated retina is similar to that found in $r d 10$ retina and that the efficiency of electrical stimulation is lower in the degenerated retina. ${ }^{43}$ Moreover, the recent work ${ }^{44}$ surveying the electrically evoked responses for different kinds of retinal neurons reported that a brief extracellular stimulus pulse elicited 10-20 Hz damped oscillations lasting several hundred milliseconds spread throughout the retina in the majority of cell types that was shown to be generated by reciprocal synapses between the cone and horizontal cell. These damped oscillations as a pulse induced phenomenon may interfere the temporal features and other characteristics of electrically evoked RGC responses. Therefore, future strategies of vision restoration apparently must avoid the evoking of the easily inducible rhythmic activity in retinal circuits and be aimed to increase the quality of image representation. Here, we present the arguments that the utilizing the fractal modulation of the stimulating pulses in amplitude or frequency and using of the fractal temporal modulations of the prestimulus background may be one of the prospective ways in a future elaboration of retinal prostheses.

\section{Noise-like behavior in physiological systems}

In nature, many objects and phenomena are described as geometric fractals or nonlinearly occur in time thus possessing the self-similar spatial or temporal structure (dynamics). They have the property of scale-invariance in space or time and characterized by a fractal dimension. ${ }^{45-49}$ The man has been evolved in a nonlinear world adapting to environmental conditions characterized by a vast diversity of fractal forms and processes. ${ }^{50,51}$ Natural noises with different statistical properties including brown and pink (fractal) noises can affect the adaptation of the organisms to the environment. ${ }^{52-54}$ Nonlinear fluctuations of physiological parameters such as the variability of heartbeats, breathing, walking, neuronal activity and other biological rhythms at different levels of the organization were demonstrated. ${ }^{55-61}$ With aging and pathology, the fractal complexity of physiological processes is lost, and the ordered (deterministic) or random (stochastic) dynamics develop. ${ }^{56,60,62,63}$ The age-induced decline in the variation of dynamics of functional connectivity was shown.$^{64}$ Sejdić E. and Lipsitz L.A. ${ }^{65}$ discussed the dual role of noise in biomedical systems and indicated the benefit of the optimal level of noise for various processes and brain activity. The 'optimality' means not only the moderate intensity (power) of noise but also the reasonable level of the stochasticity (complexity) of the process: the deterministically-chaotic (fractal) behavior of the system seems to be essential for providing its functionality. Noise can be necessary for the proper functioning of the nonlinear biological systems depended on the complex interactions of many components operating at different time scales.

Nonlinear interactions of multiple regulatory systems and environmental influences occurring over different time scales have been supposed to produce highly variable behavior in physiological processes, which can be modeled as a $1 /$ f process (cited from). ${ }^{65,66}$ Such multiscale influences include fluctuations in metabolite levels, ion channels activity, transmitter release and many others, as well as rhythmic changes of the environmental cues. Taken together, they can be sources of pink (fractal) noise generated in the output signal. ${ }^{65}$ On the other hand, Hausdorff J.M. and Peng C.-K. ${ }^{57}$ using a stochastic model, in which the output sums multiple random inputs as 
the regulatory mechanisms, concluded that the $1 /$ f fluctuations typical for many physiological processes are unlikely to be due solely to they are regulated by many inputs operated on different time scales. The concept of self-organized criticality put forward by Per $\mathrm{Bak}^{67}$ explains the ubiquity of complex geometric forms and processes in nature. ${ }^{66}$ This concept was later expanded on the functioning of the brain. ${ }^{68-70}$ The experimental evidence and data from simulations of self-organized criticality in the brain are yet controversial (for review see). ${ }^{71,72}$ Nevertheless, evidence for self-organized criticality was provided in the studies on the criticality of neuronal avalanches in various animals, the power-law noise in brain imaging data, and by data of some other investigations (cited from). ${ }^{72}$ Multiple pieces of evidence for criticality were demonstrated in experimental studies for different physiological systems. Neuronal responses of the sensory cortex are known to be highly variable (see, for example), ${ }^{73,74}$ and this variability correlates across the neuronal population..$^{75,76}$

Recently, Lin I.C. and coauthors ${ }^{77}$ created a simple model with two sources of shared variability, such as a multiplicative gain and an additive offset, which scales uniformly the activity for each neuron or, correspondently, alters responses of individual neurons to different degrees. Their results provide evidence that multiplicative and additive fluctuations modulate the whole neuronal population and explain the shared variability of neuronal populations in the sensory cortex with different impacts to the cortical coding of sensory information. Spontaneous fluctuations in brain activity occurring in the absence of sensory signals are suggested to be the dominant cause of the high variability of neural recordings. ${ }^{78-80}$ Noise in the brain arising from the action of a vast number of variables is a high-dimensional process occurring nonlinearly in time. ${ }^{50}$ The sources of internal noise of the brain include the spontaneous activity of individual neurons, network fluctuations of the local and total cortical activity, and other events. In several publications, multiple sources of noise at different levels of nervous system, and detrimental and benefited effects of noise have been discussed. ${ }^{65,79,81}$ A significant source of noise is conductance fluctuations of ionic channels, due to the stochastic dynamics of their opening/closing and the synaptic noise. ${ }^{81,82}$ High response variability is the inherent property of cortical neurons (see, for instance).$^{55}$ Softky W.R. and Koch C. ${ }^{83}$ found that variability of real cortical neurons may be predicted only in the presence of fast and robust dendritic nonlinearities or high synchronization among individual synaptic events.

The background noise of the brain has a fundamental significance for information processing. The current neuronal activity before stimulation was shown to be crucial for cortical processing of incoming stimuli. ${ }^{84-87}$ The rapid fluctuation of the state of cortical networks can influence sensory coding. Gutnisky D.A. and coauthors ${ }^{87}$ justified recently that the correlated activity of nearby neurons affects the processing of orientation signals in cortical network in the cat's visual cortex and that the distribution of ongoing states throughout a neural network provides the accuracy of population coding. On the other hand, noise helps in the detection of low-amplitude stimuli through a mechanism of "stochastic resonance." This phenomenon underlies that adding the moderate noise to the nonlinear system allows neurons to react to small, subthreshold stimuli that cannot by themselves provide the cell discharge. ${ }^{88,89}$ In visual cortex, spontaneous neural activity plays a significant role in the maturation of forming local circuits in visual cortex. ${ }^{90}$

\section{Retinal noise}

Spontaneous neuronal activity is also one of the sources of the inherent retinal noise (a background electrical activity of the retina). It is known to play a particular role in the retina in the early postnatal life. ${ }^{91}$ Spontaneous impulse activity in the RGCs is crucial in the initial establishment of synaptic connections during development ${ }^{91,92}$ and promotes further the refinement of neural circuits and brain connectivity. With maturation, the importance of evoked activity and sensory experience increasable arises. The noise in a mature retina promotes the encoding of discharges of the RGCs and the tuning of temporal contrast sensitivity in the visual cortex. ${ }^{93,94}$ Noise in the visual pathway has been hypothesized to limit its sensitivity. ${ }^{95}$ Under scotopic conditions, the spikes' noise originates mainly from the retinal output, in the photon noise and spontaneous isomerizations of rhodopsin in rod photoreceptors, which can encourage RGCs to fire. ${ }^{96}$ At the higher light levels, the possible sources of the RGC spontaneous discharge include a transduction noise in cones, fluctuations in the synaptic release of transmitters or the spike's generation (cited from). ${ }^{94}$ Spontaneous oscillations in the electrical signals of the retinal photoreceptors were found to highly contribute to a limit on visual sensitivity. ${ }^{97}$ Spontaneous fluctuations in the inward dark current in the rod's outer segment disappearing at the bright light were observed in the isolated toad retina. ${ }^{98}$ Authors described two components of electrical noise in the darkness including continuous fluctuation and occasional discrete events. The distinct events have been proposed to arise from spontaneous thermal activation of a single molecule of rhodopsin. ${ }^{98}$ The continuous noise was found to occur from fluctuations in outer-segment conductance, which are generated by spontaneous activation of cGMP phosphodiesterase without involving transducing. ${ }^{99}$ There was noted that cones are noisier than rods. ${ }^{100,101}$ Rieke F. and Baylor D.A. ${ }^{97}$ showed that in salamander retina, the dark noise of long-wavelength-sensitive cones originates from spontaneous activation of the photopigment, which is much more unstable than rhodopsin in rods. Most of the noise in short-wavelength-sensitive cones can occur at a later stage of the transduction cascade because of better stability of the visual pigment.

It is also known that the correlation of the release of neurotransmitters in the output synapses is the decisive factor in determining the flow of signals and noise in the neural circuits. ${ }^{102}$ In the darkness, a synaptic synchronization in rod's bipolar cells is the highest, and it decreases under the light conditions. The cross-synaptic synchrony reduces the current synaptic noise and ensures the accuracy of the information ${ }^{102}$, highly contributing to forming and transfer the signal in complex neural networks. This mechanism is believed to be general for the brain providing the increase the signal-to-noise ratio in the transmission of information in neural networks. ${ }^{102}$ Visual deafferentation resulting from the loss of photoreceptors during the rod degeneration of the retina in animal models of RP was associated with a paradoxical increase in spontaneous activity throughout the visual system (cited from). ${ }^{103}$ Drager U.C. and Hubel D.H. ${ }^{104}$ using extracellular single unit electrophysiological recordings from the optic nerve, superior colliculus, and visual cortex found an increase in spontaneous spiking activity and the pattern of rhythmic firing ranged between $9-14 \mathrm{~Hz}$ in $r d 1$ mice but not in healthy animals. Later, the similar conclusion was received for the rhythmicity of background spike activity from the superior colliculus in dystrophic rats (RCS, Royal College of Surgeons). ${ }^{105}$ Regular oscillatory discharges of the RGCs were demonstrated in several rodent strains with retinal 
degeneration. ${ }^{27-35}$ The RGCs of the $r d 1$ and $r d 10$ mouse exhibit an aberrant periodic activity - rhythmic discharges with an average frequency of about 7-10 Hz. ${ }^{30,106,107}$ Peaks of the spikes' activity correlated with the local field potentials (LPFs), which reflect the average synchronized excitatory input to the retinal ganglion cells.

Several mechanisms of the aberrant rhythm generation in the retina are considering. ${ }^{32,33,36,38,103}$ After the loss of photoreceptor inputs to the inner retina, it faces the resonant membrane properties of an amacrine cell that is normally restrained in the functionally intact retina (cited from) ${ }^{32}$ The electrically-coupled network of ON bipolar/ AII amacrine cell is thought to can serve as the rhythm generator. ${ }^{36}$ In the hyperpolarized AII cells, the rhythm is believed to occur due to the interaction between the fast activating sodium channels and slower potassium M-channels (cited from). ${ }^{38}$

On the other hand, studies show that no significant rewiring of the retina likely is required for driving oscillation. First of all, not all of these rhythmic oscillations seem to directly depend on photoreceptor death because hyperactivity in $r d 10$ mice retina emerges before rod degeneration starts. ${ }^{108,109}$ One explanation supposes that AII amacrine cells represent rhythm generators because their trans-membrane voltage oscillations (near $10 \mathrm{~Hz}$ ) can be seen under conditions of pharmacological isolations of these cells. ${ }^{33,37}$ Photoreceptor degeneration can also be induced pharmacologically in wild-type retina by blockade of photoreceptor input to bipolar cells. ${ }^{36,38}$, or after the light-bleaching of photoreceptors. ${ }^{33}$ These aberrant background oscillations can be abolished in both $\mathrm{rd} 1$ and rd10 mice by blocking ionotropic glutamate receptors or gap junction by meclofenamic acid. ${ }^{29,30,34,36,110,111}$ The blocking of glycinergic and gamma-aminobutyric acid receptors was also demonstrated to reduce the frequency of rhythm and increase the amplitude of LFPs. ${ }^{30,34,110}$ Intraperitoneally injected N-Methyl-N-nitrosourea (MNU) is known to lead to the apoptotic death of photoreceptors causing remodeling of the inner retina, however, sparing RGCs up to three months after injection. ${ }^{112-114}$

Besides the rhythm of discharges of the RGCs, there is observed another rhythmic electrical activity in the $r d l$ and $r d 10$ mice retinas - the LFPs, which is recording with the same frequencies as for the spiking discharges $(5-15 \mathrm{~Hz})$. LFPs reflect the changes in the extracellular voltage in the RGCs caused by correlated trans-membrane currents. With the patch clamp recordings, the rhythmicity of the excitatory and inhibitory input currents and strong sub-threshold oscillations of transmembrane potential have been shown. ${ }^{27,37,115}$ The LFPs were also revealed by electrical imaging in various brain cortical and subcortical structures. ${ }^{116,117}$ However, they have never been seen in the healthy retina of mammalian. Trenholm S. and Awatramani G.D. ${ }^{38}$ pay attention that knowledge the mechanisms underlying spontaneous retinal activity and based ways to control them could enhance the efficiency of vision restoration strategies aimed to stimulate remnant retinal circuits in the patients.

In the degenerative retinas with the loss of photoreceptors (for example, in rd1 and rd10 mice), inner retinal neurons survive and form synaptic connections to higher centers of the visual system. ${ }^{118-121}$ Visual deafferentation may result to alterations in the bipolar cell morphology ${ }^{122,123}$ but not in the RGC morphology. ${ }^{22}$ However, the pathological rhythmic RGC activity spread higher to the brain where it interferes the visual coding and information processing. ${ }^{121}$

Therefore, researchers underline that to enhance the efficiency of current strategies for restoration of vision functions the resolving of some crucial questions is needed. The main issue how we can down the aberrant activity of RGCs by external stimuli. ${ }^{32,38,103}$ The application of gap junction blockers was found to reduce RGCs hyperactivity and provide their excitation by electrical ${ }^{111}$ or optogenetic stimulation. ${ }^{124,125}$ On the other hand, the pharmacological reduction of the gapjunction coupling might disturb visual coding in subretinal electrical stimulation of RGCs, ${ }^{126}$ or optogenetic strategies aimed the bipolar cells. ${ }^{127}$ The aberrant rhythm of spike activity observing in the animal models of RP represents a source of unwanted noise that will violate the propagation of the signals from the eye to the brain and weaken a signal/noise ratio. Thus, it can decrease the efficiency of strategies to restore vision in a blind patient with RP. ${ }^{32}$ Neural noise adds the uncertainty in the signals encoding in spike trains that limits the reliably transmitted information. ${ }^{94}$ In mammalian, RGCs randomly discharge in darkness and on light, and the temporal characteristics of their firing alter depending on illumination level. ${ }^{96,128,129}$ Visual perception is known to be limited by the noise in the spike trains of RGCs and the statistical properties of the maintained discharge vary for various light levels and temporal frequency. ${ }^{128-131}$ When the frequency is below $10 \mathrm{~Hz}$, the discharge noise was mostly independent of the spikes rate131 suggesting that signal and noise might sum at specific temporal frequencies when a dynamic stimulus drives RGCs. ${ }^{94}$ Passaglia S.L. and Troy J.B. ${ }^{94}$ reported that noise in the retinal output behaves additively or multiplicatively depending on the timescale. The new knowledge and further development of technologies of restoring vision are expected to lead to an improving of bioelectronic retina implants for electrical-elicited vision and also creating alternative approaches based upon new principles of stimulation of visual system. It is supposed that future technologies may be related to selectively stimulating specific cells classes in the inner retina, to improve visual resolution and color vision. Perspectives for optogenetic approach, chemical photoswitches, and other future technologies are wide discussing. ${ }^{132}$

\section{Discussion}

\section{Parameters of electrical stimulation for visual prosthetics and temporal complexity}

The temporal parameters of stimulation and current magnitude differed in various studies in dependence on examined pathology. ${ }^{4,6}$ The retinal prosthesis, to electrically induce visual perception needs to stimulate neurons repeatedly. For the reliable quality of vision, the parameters of this rhythmic stimulation will have great importance. When direct stimulation of RGCs, electrical pulses causes the generation of an action potential without presynaptic input depolarizing the membrane. The direct stimulation can be somatic and axonal, depending on whether the RGC soma or axon is located in the immediate neighborhood of the electrode. Indirect stimulation of ganglion cells is achieved by stimulating bipolar cells that in turn post-synaptically activate ganglion cells modulating their activity. ${ }^{133-138}$ It is known that the indirect activation of RGCs with repetitive stimulation at electrical pulses rate $2 \mathrm{~Hz}$ and more reduce the number of action potentials. ${ }^{139,140}$ This phenomenon of desensitization of RGCs is supposed to involve frequency-dependent voltage-gated calcium channels in bipolar cells, and the weakening of synaptic contacts between bipolar cells and RGCs. ${ }^{139,141}$ Studies also show the fading of electrically evoked percepts in users of the retinal prosthesis within a few seconds after the onset of stimulus ${ }^{126,142,143}$ due to the adaptation of retinal neurons to the stationary, unchanging stimuli. Various techniques are tried to use to overcome the fading 
of percepts that, however, are not useful enough. ${ }^{143,144}$ The changing of the pattern of electrical stimulation of the retina by shifting the location of electrical stimulus thought not significantly to change the activated neurons. ${ }^{134}$ However, the repetitive stimulation was shown to more reliably elicit the responses of the direct RGCs activation than in the indirect stimulation. ${ }^{145}$ Directly evoked RGC responses with a latency of less or equal to $2 \mathrm{~ms}$ have the thresholds pulse widths over 0.1-5.0 ms for ON-, OFF-, and ON-OFF ganglion cell subpopulations and they are well generated using $0.1 \mathrm{~ms}$ electrical stimuli. ${ }^{145}$ These authors suggest that, for subretinal prosthetic devices, short pulses are more efficient and safe, and that direct stimulation of RGCs is preferable for reliable their activation in high-frequency stimulation. Ganglion cells can reliably respond to high frequencies in the direct stimulation, but their responses to indirect stimulation at high rates attenuates, which can contribute to the phenomenon of fading of percept observed by patients with the implant. ${ }^{145}$ It was found recently that different subpopulations of ON- and OFF-RGCs can be directly activated by short electrical pulses to generate a single burst. ${ }^{146}$

The ability of a stimulus to generate the neuronal response is dependent on the electrode location, pulse polarity and duration and other parameters such as density of electrodes and the size of stimulating array (cited from). ${ }^{42}$
In Table 1, there are summed experimental data and our theoretical suppositions concerning the significance of the pulse parameters for electrical stimulation in the retinal prosthetics. The pulse duration was shown to be an essential parameter for efficient activation of the inner retina by epiretinal stimulation. The whole cell patch-clamp recordings from the RGCs and bipolar cells in the salamander retina demonstrated that brief pulses evoke only action potentials in ganglion cells while longer pulses also stimulate glutamate release from bipolar cell terminals evoking sustained synaptic currents and, in turn, the release of gamma-aminobutyric acid and glycine from amacrine cells. ${ }^{147}$ The using of spatial patterns of electrical pulses to increase the spatial resolution of stimulation was investigated in the isolated macaque retina with a high-density multielectrode recording of RGC activity. ${ }^{148}$ The probability of RGCs activation changes when stimuli were delivered simultaneously through pairs of adjacent electrodes comparing with applying a single electrode. These data thought to be beneficial in making the new approaches to improving the spatial resolution of retinal prosthetic stimulation. ${ }^{148}$

Table I The experimentally established and hypothetical remarks on significance of the pulses parameters for electrical stimulation in the retinal prostheses

\begin{tabular}{|c|c|c|}
\hline Pulses' parameters & findings and hypotheses & authors \\
\hline \multirow[t]{5}{*}{ Duration } & $\begin{array}{l}\text { In subretinal implants, short pulses are more efficient and } \\
\text { safety. }\end{array}$ & Tsai D. et al., 145 \\
\hline & $\begin{array}{l}\text { Short ( } 25-\mathrm{ms}) \text { pulse durations are best suited to avoid axonal } \\
\text { activation and activate ganglion cells focally. }\end{array}$ & Weiland J.D., Walston S.T., Humayun M.S., $2016^{42}$ \\
\hline & $\begin{array}{l}\text { Different subpopulations of ON- and OFF-RGCs can be } \\
\text { directly activated by brief electrical pulses to generate a } \\
\text { single spike. }\end{array}$ & Jepson L.H. et al., ${ }^{146}$ \\
\hline & $\begin{array}{l}\text { Brief pulses evoke only action potentials in ganglion cells } \\
\text { while longer pulses also stimulate glutamate release from } \\
\text { bipolar cell terminals evoking sustained synaptic currents and, } \\
\text { in turn, the release of GABA and glycine from amacrine cells. }\end{array}$ & Margalit Y,Thoreson W.B., ${ }^{147}$ \\
\hline & $\begin{array}{l}\text { The threshold pulse widths for responses of ON, OFF, and } \\
\text { ON-OFF RGCs are } 0.1-5.0 \mathrm{~ms} \text {, accordingly. }\end{array}$ & Tsai D. et al., ${ }^{145}$ \\
\hline \multirow[t]{6}{*}{ Frequency } & $\begin{array}{l}\text { In the direct stimulation, the RGCs may reliably respond to } \\
\text { high frequencies. }\end{array}$ & Jepson L.H. et al., ${ }^{148}$ \\
\hline & $\begin{array}{l}\text { The stimuli at rates of } 5 \text { and } 10 \mathrm{~Hz} \text { activate photoreceptors } \\
\text { while sinusoidal stimulation at } 25 \text { and } 100 \mathrm{~Hz} \text { activates RGCs. }\end{array}$ & Twyford P., Fried S., ${ }^{149}$ \\
\hline & $\begin{array}{l}\text { In a range of stimulation rates } 4-7 \mathrm{~Hz} \text {, the ratio of the } \mathrm{ON} \\
\text { to OFF responses is maximal. }\end{array}$ & Im M., Fried S.I., 150 \\
\hline & $\begin{array}{l}\text { Responses of the ON-RGCs are reduced at high frequency } \\
(>\sim 7 \mathrm{~Hz}) \text { due to the reset. }\end{array}$ & \\
\hline & $\begin{array}{l}\text { OFF responses are robust at low rates }(<\sim 4 \mathrm{~Hz}) \text { due to } \\
\text { reduced desensitization. }\end{array}$ & \\
\hline & $\begin{array}{l}\text { In clinical trials, users prefer retinal prosthetics of } \\
\text { intermediate stimulation rates } 5-7 \mathrm{~Hz} \text {. }\end{array}$ & \\
\hline Pattern & $\begin{array}{l}\text { Patterned electrical pulses may be useful to increase the } \\
\text { spatial resolution of stimulation. }\end{array}$ & Jepson L.H. et al., ${ }^{148 ;}$ Stutzki H. et al., ${ }^{40}$ Ryu S.B. et al., ${ }^{41}$ \\
\hline
\end{tabular}


Table Continued...

\begin{tabular}{lll}
\hline Pulses' parameters & findings and hypotheses & authors \\
\hline Prestimulation & $\begin{array}{l}\text { A prestimulus pulse sequence modulating by the amplitude } \\
\text { according to random temporal patterns of natural scene may } \\
\text { cancel aberrant rhythmic retinal activity. } \\
\text { The dynamics of electrical impulses stimulating retinal } \\
\text { neurons is essential for the improved quality of electrically- } \\
\text { elicited vision. } \\
\text { In the repetitive electrical stimulation the nonlinear dynamics } \\
\text { of pulses but not the regular periodic rhythm should be used. } \\
\text { Creating the fractal fluctuation of the stimuli rate in a limited } \\
\text { range (for instance, from } 4 \text { to } 7 \text { Hz), fractal modulation of } \\
\text { the pulse amplitude / rate or applying fractal patterns in } \\
\text { the background electrical prestimulation likely may be able } \\
\text { resisting the pathological retinal rhythm and increase the } \\
\text { quality of the visual perception. }\end{array}$ \\
\hline
\end{tabular}

One of the critical aspects may be the waveform of electrical pulsatile stimuli because the commonly applying rectangular electrical pulses might activate passing axons and therefore distort the spatial pattern of neuronal activation that searches of the alternate stimuli topical. ${ }^{149}$ Twyford P. and Fried S. ${ }^{149}$ studied responses of the rabbit's RGCs to alternative sinusoidal electrical stimulation at different frequencies, and they concluded that sinusoidal signals being a useful research tool may have a limited clinical application. They revealed that patterns of responses varied between different types of RGCs; lower frequencies were more fire efficient than high frequencies. The applying of synaptic blockers showed that the stimuli at rates of 5 and $10 \mathrm{~Hz}$ activate photoreceptors while sinusoidal stimulation at 25 and $100 \mathrm{~Hz}$ activates RGCs. It is significant to take into account the fundamental temporal properties of responses of RGCs to intermittent electrical stimuli to provide the stimulation the retinal neurons at an appropriate rate. Im M and Fried $\mathrm{SI}^{150}$ have obtained with cellattached patch electrode distinct responses of ON and OFF types RGCs of the rabbit retina with epiretinal explant to repetitive electric stimulation at different stimulation rates. In a range of stimulation rates $4-7 \mathrm{~Hz}$, the ratio of the $\mathrm{ON}$ to $\mathrm{OFF}$ responses was maximal. The authors demonstrated that responses of the ON-RGCs were reduced at high frequency $(>\sim 7 \mathrm{~Hz})$ due to the reset and OFF responses were robust at low rates $(<\sim 4 \mathrm{~Hz})$ due to reduced desensitization. ${ }^{150}$ These results can explain the observed in clinical trials preference by users of retinal prosthetics of intermediate stimulation rates $5-7 \mathrm{~Hz} .{ }^{126,151-153}$

It has been recently shown that irrespective of the type of degeneration, the RGC activity evoked by electrical stimulation is much lower in the degenerated retina compared to wild-type retina. ${ }^{43}$ In this study, a prestimulus pulse sequence was used to cancel the rhythmic retinal activity. Retinas of rd10 mice and MNU-treated mice were pre-stimulated with a multi $(10 \mathrm{x})$ biphasic current impulses $(80$ $\mu \mathrm{A}, 1000 \mu \mathrm{s}, 1 \mathrm{~Hz}$ ). After the disappearance of the aberrant LFP's and burst oscillations, a single biphasic pulse was applied. Under conditions of the abolishment of pathological background rhythms of network and RGCs activity, this study found an enhancement of the stimulation efficiency, which was apparent, however, not in the majority of tested cells. ${ }^{43}$ Authors note that this approach to modify stimulation protocols could help improving the efficiency of visual prostheses.

In the recent study of Ryu S.B. and coauthors ${ }^{41}$ retinal patches from $r d l$ mice were isolated and mounted on a planar microelectrode array. Trains of 20 pulses $(1 \mathrm{~Hz}, 500 \mu \mathrm{s})$ were applied at 1 -second intervals to characterize the behavior of RGC responses under the modulation of pulse amplitude. The pulse amplitudes were modulated according to random temporal patterns of brightness predetermined from the time-series of the intensity of the natural scene. These results provide evidence that valuable visual functions may be enhanced using retinal stimulation techniques based on the amplitude modulation. Another essential aspect we suppose needed to be considered for the improved quality of electrically-elicited vision is the dynamics of electrical impulses stimulating retinal neurons. We guess that the quality of vision must increase if to provide the nonlinear dynamics of a repetition of electrical signals but not use the regular periodic rhythm. If technical capabilities allow this, then the inter-stimulus interval should vary by the power law $1 / \mathrm{f}$ thus creating the fractal fluctuation in stimulation rate in a particular, limited range, for instance, from 4 to $7 \mathrm{~Hz}$. This assumption is based on abovementioned numerous literature data evidenced that fractal (deterministic-chaotic) dynamics characterize healthy physiological processes, and pathology leads to the development of entirely random, stochastic fluctuations or, conversely, to the deterministic rhythm of ordered oscillations (for review see). ${ }^{48,49}$

We forwarded the hypothesis that intimate link exists between the healthy maturation and maintenance of the optimal complexity of neural networks and the functional activity of the brain and the fractal complexity of visual, sound cues and other complex-structured signals in the environment that accompany and influence upon a person throughout his life. ${ }^{48}$ The simplification of the temporal and spatial structure of environmental cues can contribute to the manifestation and progression of already an existing hidden pathology, or provoke its development. The use of fractal visual-, audio-, electrical stimulation and complex-structured stimuli of other modalities may enhance the effectiveness of strategies for a recovery in the structure and function of the retina and brain via affecting the neuroplasticity. ${ }^{48,51}$ One can expect that the using of nonlinear stimulation therapy would be useful in a variety of situations including eye diseases such as amblyopia, ${ }^{153}$ glaucoma and age-related macular dystrophy.

It is likely that the increased potential of neuronal plasticity could significantly enhance the effectiveness of the treatment. The complexstructured stimuli of the fractal (deterministic-chaotic) dynamics, in our opinion, should impact the neuronal plasticity more efficiently than periodic incentives of a deterministic dynamics, which are used currently in the light- and electrical stimulation therapy. The appearance of the aberrant deterministic rhythm in the spontaneous 
activity of the RGCs and LFPs in animal retinas with photoreceptor degenerations instead of the nonlinear noise, which is characteristic for the wild-type retina, is associated with deafferentation of the retina. This factor cannot be eliminated, but it is possible to try to cancel pathological rhythm, for instance, by the prestimulation as in the mentioned above study ${ }^{43}$ or to significantly weaken the consequences related to the spontaneous rhythmic retinal activity. These harmful consequences may include an increase in the level of noise that hinders signal coding and processing in the higher departments of the visual system and an acceleration of the retinal degeneration. We hypothesize the negative role (an exacerbating impact of deafferentation) of an ordered rhythmic activity in the retina in a formation of abnormal synaptic contacts during retinal remodeling and the distortion of the complexity of neural circuits in the retina and the brain of animals and patients with hereditary photoreceptor degeneration.

On the other hand, we believe that complex-structured optical and electrical stimulation therapy can be promising approaches providing both tuning the temporal sensitivity of the visual system and activation of the neuronal plasticity throughout the visual pathway. It is true, first of all, for stimulation therapy of diseases not associated with the massive death of photoreceptors and rewiring of neuronal circuits in the inner retina. The situation is more complicated in RP and other blinding pathologies, in which electrical impulses, directly or indirectly inducing RGCs, replace visual information transmitted in a healthy retina via photoreceptors. In these cases, a new approach we propose for retinal prosthetics consists in the application the fractal modulation of the stimulating pulses in amplitude and frequency as well as the fractal temporal patterns in the background electrical prestimulation to resist the pathologic rhythmic activity in retinal circuits and increase the quality of the visual perception.

\section{Conclusive remarks}

Spontaneous fluctuations in neuronal activity are known to result in the high variability of neural recordings, complex nonlinear dynamics of which is characteristic of the functional activity of the healthy brain. Different impacts of noise to sensory processing in the brain and the retina and the sources of neuronal noise are attracting the attention of many researchers and have been extensively studying and discussing. For example, noise can help detecting of low-amplitude stimuli through a phenomenon of "stochastic resonance." In visual cortex, spontaneous neural activity was shown to play a significant role in the maturation and forming local circuits in visual cortex. For retinal and brain's functions, the necessity of the optimal level (by the intensity and nonlinear complexity) of the noise has been evidenced in many studies as conditions for the proper functioning of the nonlinear biological systems. The highly variable behavior of many healthy physiological systems including the spontaneous retinal activity is simplified in pathology and became very ordered (periodic fluctuations) or is characterized by entirely uncorrelated random oscillations.

The loss of photoreceptors due to the retinal degeneration and sensory deafferentation was associated with a paradoxical increase in spontaneous activity in the retina and throughout the visual system and the pathologic rhythmic pattern of spike activity correlated with the LPFs reflecting the average synchronized excitatory input to the RGCs. A wide range of electrical stimulation methods aimed at activation the retina and the related downstream structures in the brain are currently known. In retinal implants, artificial induction of electrically-elicited visual sensations is applied in persons blind due to RP and ARMD. The right choice of the parameters of electrical stimuli is of great importance for obtaining reliable responses from the RGCs and transmission encoded visual information to the brain. The temporal parameters of stimulation can be one of the crucial factors to the further innovation development of these approaches. We hypothesize that an aberrant rhythm of spontaneous RGCs activity (the deterministic dynamics instead chaotic fluctuations) can aggravate the impact of deafferentation and contribute in a formation of abnormal synaptic contacts during retinal remodeling and the distortion of the complexity of neural circuits in animals and patients with hereditary retinal degenerations.

We guess that the optical and electrical stimulation therapy using the complex-structured (fractal) signals can be promising approaches providing both tuning the temporal sensitivity of the visual system and activation of the plasticity of neurons throughout the visual pathway. Future strategies for vision restoration in patients with RP and ARMD apparently must be aimed to avoid the rhythmic activity in retinal circuits and to increase the quality of image representation. Here, we present the arguments that the utilizing the fractal modulation of the stimulating pulses in amplitude or frequency as well as using fractal temporal patterns in the background electrical prestimulation may be one of the prospective ways in future elaboration successful retinal prosthesis.

\section{Acknowledgments}

None.

\section{Conflicts of interest}

The author declares that there is no conflict of interest regarding the publication of this paper.

\section{Funding}

The author received no financial support for research, authorship, and/or publication of this article.

\section{Authorship contribution}

Concept, search, analysis and interpretation of the literature, hypotheses, writing: Marina Zueva.

\section{References}

1. Morimoto T, Miyoshi T, Fujikado T, et al. Electrical stimulation enhances the survival of axotomized retinal ganglion cells In vivo. Neuroreport. 2002;13(2):227-230.

2. Morimoto T, Fujikado T, Choi JS, et al. Transcorneal electrical stimulation promotes the survival of photoreceptors and preserves retinal function in royal college of surgeons rats. Invest Ophthalmol Vis Sci. 2007;48(10):4725-4732.

3. Ni YQ, Gan DK, Xu HD, et al. Neuroprotective effect of transcorneal electrical stimulation on light-induced photoreceptor degeneration. Exp Neurol. 2009;219(2):439-452.

4. Wang X, Mo X, Li D, et al. Neuroprotective effect of transcorneal electrical stimulation on ischemic damage in the rat retina. Exp Eye Res. 2011;93(5):753-760.

5. Tao Y, Chen T, Liu B, et al. The transcorneal electrical stimulation as a novel therapeutic strategy against retinal and optic neuropathy: a review of experimental and clinical trials. Int J Ophthalmol. 2016;9(6):914-919. 
6. Fujikado T, Morimoto T, Matsushita K, et al. Effect of transcorneal electrical stimulation in patients with nonarteritic ischemic optic neuropathy or traumatic optic neuropathy. Jpn J Ophthalmol. 2006;50(3):266-273.

7. Gekeler F, Messias A, Ottinger M, et al. Phosphenes electrically evoked with DTL electrodes: a study in patients with retinitis pigmentosa glaucoma, and homonymous visual field loss and normal subjects. Invest Ophthalmol Vis Sci. 2006;47(11):4966-4974.

8. Inomata $\mathrm{K}$, Shinoda $\mathrm{K}$, Ohde $\mathrm{H}$, et al. Transcorneal electrical stimulation of retina to treat longstanding retinal artery occlusion. Graefes Arch Clin Exp Ohthalmol. 2007;245(12):1773-1780.

9. Gall C, Fedorov AB, Ernst L, et al. Repetitive transorbital alternating current stimulation in optic neuropathy. Neuro Rehabilitation. 2010;27(4):335-341.

10. Schatz A, Röck T, Naycheva L, et al. Transcorneal electrical stimulation for patients with retinitis pigmentosa: a prospective, randomized, shamcontrolled exploratory study. Invest Ophthalmol Vis Sci. 2011;52(7):44854496.

11. Shinoda K, Imamura Y, Matsuda S, et al. Transcutaneous Electrica Retinal Stimulation Therapy for Age-Related Macular Degeneration. Open Ophthalmol J. 2008;2:132-136.

12. Chaikin L, Kashiwa K, Bennet M, et al. Microcurrent stimulation in the treatment of dry and wet macular degeneration. Clin Ohthalmol. 2015;9:2345-2353.

13. Ma Z, Cao P, Sun P, et al. Optical imaging of visual cortical responses evoked by transcorneal electrical stimulation with different parameters. Invest Ophthalmol Vis Sci. 2014;55(8):5320-5331.

14. Sergeeva EG, Henrich-Noack P, Gorkin AG, et al. Preclinical model of transcorneal alternating current stimulation in freely moving rats. Restor Neurol Neurosci. 2015;33(5):761-769.

15. Sehic A, Guo S, Cho KS, et al. Electrical Stimulation as a Means for Improving Vision. Am J Pathol. 2016;186(11):2783-2797.

16. Hanif AM, Kim MK, Thomas JG, et al. Whole-eye electrical stimulation therapy preserves visual function and structure in $\mathrm{P} 23 \mathrm{H}-1$ rats. Exp Eye Res. 2016;149:75-83.

17. Nibuya M, Morinobu S, Duman RS. Regulation of BDNF and trkB mRNA in rat brain by chronic electroconvulsive seizure and antidepressant drug treatments. J Neurosci. 1995;15(11):7539-7547.

18. Al-Majed AA, Brushart TM, Gordon T. Electrical stimulation accelerates and increases expression of BDNF and trkB mRNA in regenerating rat femoral motoneurons. Eur J Neurosci. 2000;12(12):4381-4390.

19. Morimoto T, Miyoshi T, Matsuda S, et al. Transcorneal electrical stimulation rescues axotomized retinal ganglion cells by activating endogenous retinal IGF-1 system. Invest Ophthalmol Vis Sci. 2005; 46(6):2147-2155

20. Morimoto T, Miyoshi T, Sawai H, et al. Optimal parameters of transcorneal electrical stimulation (TES) to be neuroprotective of axotomized RGCs in adult rats. Exp Eye Res. 2010;90(2):285-291.

21. Marc RE, Jones BW, Anderson JR, et al. Neural reprogramming in retinal degeneration. Invest Ophthalmol Vis Sci. 2007;48(7):3364-3371.

22. Mazzoni F, Novelli E, Strettoi E. Retinal ganglion cells survive and maintain normal dendritic morphology in a mouse model of inherited photoreceptor degeneration. J Neurosci. 2008;28(52):14282-14292.

23. Phillips MJ, Otteson DC, Sherry DM. Progression of neuronal and synaptic remodeling in the $\mathrm{rd} 10$ mouse model of retinitis pigmentosa. $J$ Comp Neurol. 2010;518(11):2071-2089.

24. Jones BW, Kondo M, Terasaki H, et al. Retinal remodeling. Jpn J Ophthalmol. 2012;56(4):289-306.
25. Santos A, Humayun MS, de Juan E, et al. Preservation of the inner retina in retinitis pigmentosa: a morphometric analysis. Arch Ophthalmol. 1997;115(4):511-515.

26. Cameron MA, Al Abed A, Buskila Y, et al. Differential effect of brief electrical stimulation on voltage-gated potassium channels. J Neurophysiol. 2017;117(5):2014-2024.

27. Margolis DJ, Newkirk G, Euler T, et al. Functional stability of retinal ganglion cells after degeneration-induced changes in synaptic input. $J$ Neurosci. 2008;28(25):6526-6536.

28. Stasheff SF. Emergence of sustained spontaneous hyperactivity and tem $\neg$ porary preservation of OFF responses in ganglion cells of the retinal de $\neg$ generation (rd1) mouse. J Neurophysiol. 2008;99(3):1408-1421.

29. Borowska J, Trenholm S, Awatramani GB. An intrinsic neural oscillator in the degenerating mouse retina. J Neurosci. 2011;31(13):5000-5012.

30. Menzler J, Zeck G. Network oscillations in rod-degenerated mouse retinas. J Neurosci. 2011;31(6):2280-2291.

31. Goo YS, Ahn KN, Song YJ, et al. Spontaneous Oscillatory Rhythm in Retinal Activities of Two Retinal Degeneration (rd1 and rd10) Mice. Korean J Physiol Pharmacol. 2011;15(6):415-422.

32. Margolis DJ, Detwiler PB. Cellular Origin of Spontaneous Ganglion Cell Spike Activity in Animal Models of Retinitis Pigmentosa. J Ophthalmol. 2011;2011:6.

33. Margolis DJ, Gartland AJ, Singer JH, et al. Network oscillations drive correlated spiking of ON and OFF ganglion cells in the rd1 mouse model of retinal degeneration. PLoS One. 2014;9(1):e86253.

34. Biswas S, Haselier C, Mataruga A, et al. Pharmacological Analysis of Intrinsic Neuronal Oscillations in rd10 Retina. PLoS One. 2014;9(6):e99075.

35. Goo YS, Park DJ, Ahn JR, et al. Spontaneous Oscillatory Rhythms in the Degenerating Mouse Retina Modulate Retinal Ganglion Cell Responses to Electrical Stimulation. Front Cell Neurosci. 2016;9:512.

36. Trenholm S, Borowska J, Zhang J, et al. Intrinsic oscillatory activity arising within the electrically coupled AII amacrine-ON cone bipolar cell network is driven by voltage-gated $\mathrm{Na}+$ channels. J Physiol. 2012;590(10):2501-2517

37. Choi H, Zhang L, Cembrowski MS, et al. Intrinsic bursting of AII amacrine cells underlies oscillations in the $\mathrm{rd} 1$ mouse retina. $J$ Neurophysiol. 2014;112(6):1491-1504.

38. Trenholm S, Awatramani GD. Origins of spontaneous activity in the degenerating retina. Front Cell Neurosci. 2015;9:277.

39. Ryu SB, Ye JH, Goo YS, et al. Decoding of temporal visual information from electrically evoked retinal ganglion cell activities in photoreceptordegenerated retinas. Invest Ophthalmol Vis Sci. 2011;52(9):6271-6278.

40. Stutzki H, Helmhol F, Eickenscheidt M, et al. Subretinal electrical stimulation reveals intact network activity in the blind mouse retina. $J$ Neurophysiol. 2016;116(4):1684-1693.

41. Ryu SB, Choi JW, Ahn KN, et al. Amplitude Modulation-based Electrical Stimulation for Encoding Multipixel Spatiotemporal Visual Information in Retinal Neural Activities. J Korean Med Sci. 2017;32(6):900-907.

42. Weiland JD, Walston ST, Humayun MS. Electrical Stimulation of the Retina to Produce Artificial Vision. Annu Rev Vis Sci. 2016;2:273-294.

43. Haselier C, Biswas S, Rösch S, et al. Correlations between specific patterns of spontaneous activity and stimulation efficiency in degenerated retina. PLoS ONE. 2017;12(12):e0190048

44. Tsai D, Morley JW, Suaning GJ, et al. Survey of electrically evoked responses in the retina - stimulus preferences and oscillation among neurons. Sci Rep. 2017;7(1):13802. 
45. Mandelbrot B. The Fractal Geometry of Nature. Freeman, San Francisco, 1983.

46. Feder J Fractals. Plenum, New York, 1988.

47. Bassingthwaighte JB, Liebovitch LS, West BJ. Fractal Physiology. Oxford, New York, 1994.

48. Zueva MV. Fractality of sensations and the brain health: the theory linking neurodegenerative disorder with distortion of spatial and temporal scale-invariance and fractal complexity of the visible world. Front Aging Neurosci. 2015;7:135.

49. Zueva MV. Nonlinear stimulation technologies to enhance the efficiency of the therapy of brain disorders and efficacy of cognitive training. Int $J$ Adv Res. 2017a;5(8):250-269.

50. Longtin A. Effects of Noise on Nonlinear Dynamics. In: Beuter A, Glass L, Mackey MC, et al. editors. Nonlinear Dynamics in Physiology and Medicine. Springer Science-Business Media, 2003;46:149-189.

51. Zueva MV. Dynamic Fractal Flickering as a Tool in Research of NonLinear Dynamics of the Evoked Activity of a Visual System and the Possible Basis for New Diagnostics and Treatment of Neurodegenerative Diseases of the Retina and Brain. World Appl Sci J. 2013;27(4):462-468.

52. Halley JM. Ecology, evolution and 1/ f -noise. Trends Ecol Evol. 1996;11(1):33-37.

53. Halley JM, Inchausti P. The increasing importance of $1 /$ f noise as models of ecological variability. Fluct Noise Lett. 204;4(2): R1-R26.

54. Vasseur DA, Yodzis P. The color of environmental noise. Ecology. 2004;85(4):1146-1152.

55. Teich MC, Lowen SB. Fractal patterns in auditory nerve-spike trains IEEE Engr Med Biol. 1994;13:197-202.

56. Hausdorff JM, Peng CK, Ladin Z, et al. Is walking a random walk: evidence for long-range correlations in stride interval of human gait. $J$ Appl Physiol. 1995;78(1):349-358.

57. Hausdorff JM, Peng C. Multiscaled randomness: A possible source of 1/f noise in biology. Physical Review E. 1996;54(2):2154-2157.

58. Teich MC, Heneghan C, Lowen SB, et al. Fractal character of the neural spike train in the visual system of the cat. J Opt Soc Am A. 1997;14(3):529 546.

59. Goldberger AL. Fractal variability versus pathologic periodicity: complexity loss and stereotypy in disease. Perspect Biol Med. 1997;40(4):543-561.

60. Peng C-K, Hausdorff JM, Goldberger AL. Fractal mechanisms in neuronal control: human heartbeat and gait dynamics in health and disease. In: Jan Walleczek Ed. Self-Organized Biological Dynamics and Nonlinear Control: Toward Understanding Complexity, Chaos and Emergent Function in Living Systems. Cambridge University Press. 2000;66-96.

61. Lowen SB, Ozaki T, Kaplan E, et al. Fractal features of dark, maintained, and driven neural discharge in the cat visual system. Methods. 2001;24:377-394.

62. Lipsitz LA, Goldberger AL. Loss of "complexity" and aging. JAMA 1992;267(13):1806-1809.

63. Sleimen-Malkoun R, Temprado JJ, Hong SL. Aging induced loss of complexity and dedifferentiation: consequences for coordination dynamics within and between brain, muscular and behavioral levels. Front Aging Neurosci. 2014;6:140.

64. Chen Y, Wang W, Zhao X, et al. Age-Related Decline in the Variation of Dynamic Functional Connectivity: A Resting State Analysis. Front Aging Neurosci. 2017;9:203.
65. Sejdić E, Lipsitz LA. Necessity of noise in physiology and medicine. Comput Methods Programs Biomed. 2013;111(2):459-470.

66. Hoop B, Peng CK. Fluctuations and fractal noise in biological membranes. J Membr Biol. 2000;177(3):177-185.

67. Bak P, Tang C, Wiesenfeld K. Self-organized criticality: An explanation of the 1/f noise. Phys Rev Lett. 1987;59(4):381-384.

68. Bilder RM, Knudsen KS. Creative cognition and systems biology on the edge of chaos. Front Psychol. 2014;5:1104.

69. Kitzbichler MG, Smith ML, Christensen SR, Bullmore E. Broadband Criticality of Human Brain Network Synchronization. PLoS Comput Biol. 2009;5(3): e1000314.

70. Timme NM, Marshall NJ, Bennett N, et al. Criticality Maximizes Complexity in Neural Tissue. Front Physiol. 2016;7:425.

71. Beggs JM, Timme N. Being critical of criticality in the brain. Front. Physiol. 2012;3:163.

72. Hesse J, Gross T. Self-organized criticality as a fundamental property of neural systems. Front Syst Neurosci. 2014;8:166.

73. Tolhurst DJ, Movshon JA, Dean AF. The statistical reliability of signals in single neurons in cat and monkey visual cortex. Vision Res. 1983;23(8):775-785.

74. Vogels R, Spileers W, Orban GA. The response variability of striate cortical neurons in the behaving monkey. Exp Brain Res. 1989;77(2):432436.

75. Shadlen MN, Newsome WT. The variable discharge of cortical neurons: implications for connectivity, computation, and information coding. $J$ Neurosci. 1998;18(10):3870-3896.

76. Averbeck BB, Lee D. Effects of noise correlations on information encoding and decoding. J Neurophysiol. 2006;95(6):3633-3644.

77. Lin IC, Okun M, Carandini M, et al. The Nature of Shared Cortical Variability. Neuron. 2015;87(3):644-656.

78. Faisal AA. Noise in neurons and other constrains. In: N Le Novere Editor Computational Systems Neurobiology. Springer Science Business media, Dordrecht; 2012. p. 227-257.

79. Faisal AA, Selen LP, Wolpert DM. Noise in the nervous system. Nat Rev Neurosci. 2008; 9(4):292-303.

80. Hartmann C, Lazar A, Nessler B, et al. Where's the Noise? Key Features of Spontaneous Activity and Neural Variability Arise through Learning in a Deterministic Network. PLoS Comput Biol. 2015;11(12):e1004640.

81. DeFelice LJ. Introduction to membrane noise. Plenum Press, New York, 1981

82. Steinmetz PN, Manwani A, Koch C, et al. Subthreshold voltage noise due to channel fluctuations in active neuronal membranes. J Comput Neurosci. 2000; 9:133-148

83. Softky WR, Koch C. The highly irregular firing of cortical cells is inconsistent with temporal integration of random EPSPs. J Neurosci. 1993;13(1):334-350.

84. Arieli A, Sterkin A, Grinvald A, et al. Dynamics of ongoing activity: explanation of the large variability in evoked cortical responses. Science. 1996;273:1868-1871

85. Chance FS, Abbott LF, Reyes AD. Gain modulation from background synaptic input. Neuron. 2002;35:773-782.

86. Azouz R, Gray CM. Adaptive coincidence detection and dynamic gain control in visual cortical neurons in vivo. Neuron. 2003;37:513-523. 
87. Gutnisky DA, Beaman CB, Lew SE, et al. Spontaneous fluctuations in visual cortical responses influence population coding accuracy. Cereb Cortex. 2017;27(2):1409-1427.

88. Anderson JS, Lampl I, Gillespie DC, et al. The contribution of noise to contrast invariance of orientation tuning in cat visual cortex. Science. 2000;290(5498):1968-1972.

89. Stacey WC, Durand DM. Synaptic noise improves detection of subthreshold signals in hippocampal CA1 neurons. J Neurophysiol. 2001;86(3):1104-1112.

90. Katz LC, Shatz CJ. Synaptic activity and the construction of cortical circuits. Science. 1996;274(5290):1133-1138.

91. Tian N. Synaptic activity, visual experience and the maturation of retinal synaptic circuitry. J Physiol. 2008;586(18):4347-4355.

92. Feller M, Blankenship A. The function of the retina prior to vision: The phenomenon of retinal waves and retinotopic refinement. In: LM. Chalupa and RW. Williams Editors. Eye, retina, and visual system of the mouse. MIT Press: Cambridge, Mass. 2008, p. 343-351.

93. Movshon JA, Thompson ID, Tolhurst DJ. Spatial and temporal contrast sensitivity of neurons in areas 17 and 18 of the cat's visual cortex. $J$ Physiol. 1978;283:101-120.

94. Passaglia CL, Troy JB. Impact of Noise on Retinal Coding of Visua Signals. J Neurophysiol. 2004;92(2):1023-1033.

95. Barlow H. Retinal Noise and Absolute Threshold. J Opt Society Am 1956;46(8):634-639.

96. Barlow HB, Levick WR, Yoon M. Responses to single quanta of light in retinal ganglion cells of the cat. Vision Res. 1971; Suppl3:87-101.

97. Rieke F, Baylor DA. Origin and functional impact of dark noise in retinal cones. Neuron. 2000;26(1):181-186.

98. Baylor DA, Matthews G, Yau KW. Two components of electrical dark noise in toad retinal rod outer segments. J Physiol. 1980;309:591-621.

99. Rieke F, Baylor DA. Molecular origin of continuous dark noise in rod photoreceptors. Biophys J. 1996;71(15):2553-2572.

100. Baylor DA, Nunn BJ, Schnapf JL. The photocurrent, noise and spectral sensitivity of rods of the monkey Macaca fascicularis. J Physiol. 1984;357:575-607.

101. Schnapf JL, Nunn BJ, Meister M, et al. Visual transduction in cones of the monkey Macaca fascicularis. J Physiol. 1990;427: 681-713.

102. Grimes WN, Hoon M, Briggman KL, et al. Cross-synaptic synchrony and transmission of signal and noise across the mouse retina. Calabrese $R L$ ed. eLife. 2014;3:e03892.

103. Zeck G. Aberrant activity in degenerated retinas revealed by electrical imaging. Front Cell Neurosci. 2016;10:25.

104. Drager UC, Hubel DH. Studies of visual function and its decay in mice with hereditary retinal degeneration. J Comp Neurol. 2008;180(1):85114.

105. Sauvè Y, Girman SV, Wang S, et al. Progressive visual sensitivity loss in the Royal College of Surgeons rat: perimetric study in the superior colliculus. Neurosci. 2001;103(1):51-63.

106. Menzler J, Channappa L, Zeck G. Rhythmic ganglion cell activity in bleached and blind adult mouse retinas. PLOS ONE. 2014; 9:e106047.

107. Greschner M, Field GD, Li PH, et al. A polyaxonal amacrine cell population in the primate retina. $J$ Neurosci. 2014;34:3597-3606.

108. Stasheff SF, Shankar M, Andrews MP. Developmental time course distinguishes changes in spontaneous and light-evoked retinal ganglion cell activity inrd1andrd10mice. J Neurophysiol. 2011;105(6):3002-3009.
109. Jae SA, Ahn KN, Kim JY, et al. Electrophysiological and Histologic Evaluation of the Time Course of Retinal Degeneration in the rd10 Mouse Model of Retinitis Pigmentosa. Korean J Physiol Pharmacol. 2013;17(3):229-235.

110. Ye JH, Goo YS. The slow wave component of retinal activity in $\mathrm{rd} / \mathrm{rd}$ mice recorded with a multi-electrode array. Physiol Meas. 2007;28(9):1079_ 1088

111. Toychiev AH, Ivanova E, Yee CW, et al. Block of gap junctions eliminates aberrant activity and restores light responses during retinal degeneration. J Neurosci. 2013;33(35):13972-13977.

112. Nagar S, Krishnamoorthy V, Cherukuri P, et al. Early remodeling in an inducible animal model of retinal degeneration. Neuroscience. 2009;160(2):517-529

113. Tsuruma K, Yamauchi M, Inokuchi Y, et al. Role of oxidative stress in retinal photoreceptor cell death in N-methyl-N-nitrosourea-treated mice. J Pharmacol Sci. 2012;118(3):351-362.

114. Rösch S, Johnen S, Mataruga A, et al. Selective photoreceptor degeneration by intravitreal injection of N-methyl-N-nitrosourea. Invest Ophthalmol Vis Sci. 2014;55(3):1711-1723.

115. Yee $\mathrm{CW}$, Toychiev AH, Ivanova E, et al. Aberrant synaptic input of retinal ganglion cells varies with morphology in a mouse model of retinal degeneration. J Comp Neurol. 2014;522:4085-4099.

116. Viventi J, Kim DH, Vigeland L, et al. Flexible, foldable, actively multiplexed, high-density electrode array for mapping brain activity in vivo. Nat Neurosci. 2011;14(12):1599-1605.

117. Ferrea E, Maccione A, Medrihan L, et al. Large-scale, high-resolution electrophysiological imaging of field potentials in brain slices with microelectronic multielectrode arrays. Front Neural Circuits. 2012;6:80.

118. Bi AD, Cui JJ, Ma YP, et al. Ectopic expression of a microbialtype rhodopsin restores visual responses in mice with photoreceptor degeneration. Neuron. 2006;50(1):23-33.

119. Lagali PS, Balya D, Awatramani GB, et al. Light-activated channels targeted to $\mathrm{ON}$ bipolar cells restore visual function in retinal degeneration. Nat Neurosci. 2008;11(6):667-675.

120. Lin B, Koizumi A, Tanaka N, et al. Restoration of visual function in retinal degeneration mice by ectopic expression of melanopsin. Proc Natl Acad Sci USA. 2008;105(41):16009-16014.

121. Ivanova $\mathrm{E}$, Yee $\mathrm{CW}$, Baldoni $\mathrm{R}$, et al. Aberrant activity in retina degeneration impairs central visual processing and relies on $\mathrm{Cx} 36$ containing gap junctions. Exp Eye Res. 2015;150:81-90.

122. Strettoi E, Porciatti V, Falsini B, et al. Morphological and functional abnormalities in the inner retina of the $\mathrm{rd} / \mathrm{rd}$ mouse. J Neurosci. 2002;22(13):5492-5504.

123. Gargini C, Terzibasi E, Mazzoni F, et al. Retinal organization in the retinal degeneration 10 (rd10) mutant mouse: a morphological and ERG study. $J$ Comp Neurol. 2007;500(2):222-238.

124. Barrett JM, Degenaar P, Sernagor E. Blockade of pathological retina ganglion cell hyperactivity improves optogenetically evoked light responses in rd1 mice. Front Cell Neurosci. 2015;9:330.

125. Zrenner E, Bartz-Schmidt KU, Benav H, et al. Subretinal elec $\neg$ tronic chips allow blind patients to read letters and combine them to words. Proc Biol Sci. 2011;278:1489-1497.

126. van Wyk M, Pielecka-Fortuna J, Löwel S, et al. Restoring the ON switch in blind retinas: opto-mGluR6, a next-generation, cell-tailored optogenetic tool. PLoS Biol. 2015;13:e1002143.

127. Kuffler SW, Fitzhugh R, Barlow HB. Maintained activity in the cat's retina in light and darkness. J Gen Physiol. 1957;40(5):683-702. 
128. Rodieck RW. Maintained activity of cat retinal ganglion cells. $J$ Neurophysiol. 1967;30(5):1043-1071.

129. Frishman LJ, Levine MW. Statistics of the maintained discharge of cat retinal ganglion cells. J Physiol. 1983;339 475-494.

130. Troy JB. Steady discharges of X and Y retinal ganglion cells of cat under photopic illumination. Vis Neurosci. 1992;9(6):535-553.

131. Yue L, Weiland JD, Roska B, et al. Retinal stimulation strategies to restore vision: Fundamentals and systems. Prog Ret Eye Res. 2016;53:21-47.

132. Behrend MR, Ahuja AK, Humayun MS, et al. Selective labeling of retinal ganglion cells with calcium indicators by retrograde loading in vitro. $J$ Neurosci Methods. 2009;179(2):166-172.

133. Behrend MR, Ahuja AK, Humayun MS, et al. Resolution of the epiretinal prosthesis is not limited by electrode size. IEEE Trans Neural Syst Rehabi Eng. 2011;19(4):436-442.

134. Greenberg RJ, Velte TJ, Humayun MS, et al. A computational model of electrical stimulation of the retinal ganglion cell. IEEE Trans Biomed Eng. 1999;46(5):505-514.

135. Weitz AC, Behrend MR, Lee NS, et al. Imaging the response of the retina to electrical stimulation with genetically encoded calcium indicators. $J$ Neurophysiol. 2013;109(7):1979-1988.

136. Weitz AC, Nanduri D, Behrend MR, et al. Improving the spatial resolution of epiretinal implants by increasing stimulus pulse duration. Sci Transl Med. 2015;7(318):318ra203.

137. Grosberg LE, Ganesan K, Goetz GA, et al. Activation of ganglion cells and axon bundles using epiretinal electrical stimulation. J Neurophysiol. 2017;118(3):1457-1471.

138. Freeman DK, Rizzo JF, Fried SI. Encoding visual information in retinal ganglion cells with prosthetic stimulation. $J$ Neural Eng. 2011;8(3):035005

139. Hadjinicolaou AE, Savage CO, Apollo NV, et al. Optimizing the electrical stimulation of retinal ganglion cells. IEEE Trans Neural Syst Rehabil Eng. 2015;23(2):169-178.

140. Freeman DK, Eddington DK, Rizzo JF, et al. Selective activation of neuronal targets with sinusoidal electric stimulation. J Neurophysiol. 2010;104(5):2778-2791.
141. Pérez Fornos A, Sommerhalder J, da Cruz L, et al. Temporal properties of visual perception on elec $\neg$ trical stimulation of the retina. Invest Ophthalmol Vis Sci. 2012;53(6):2720-2731.

142. Stingl K, Bartz-Schmidt KU, Besch D, et al. Subretinal visual implant Alpha IMS - clinical trial interim report. Vis Res. 2015;111(Pt B):149160.

143. Hafed ZM, Stingl K, Bartz-Schmidt KU, et al. Oculomotor behavior of blind patients seeing with a subretinal visual implant. Vis Res. 2015;118:119-131.

144. Tsai D, Morley JW, Suaning GJ, et al. Direct activation and temporal response properties of rabbit retinal ganglion cells following subretinal stimulation. J Neurophysiol. 2009;102(5):2982-2993.

145. Jepson LH, Hottowy P, Mathieson K, et al. Focal Electrical Stimulation of Major Ganglion Cell Types in the Primate Retina for the Design of Visual Prostheses. J Neurosci. 2013;33(17):7194-7205.

46. Margalit Y, Thoreson WB. Inner Retinal Mechanisms Engaged by Retinal Electrical Stimulation. Invest Ophthalmol Vis Sci. 2006;47(6):2606-2612.

147. Jepson LH, Hottowy P, Mathieson K, et al. Spatially patterned electrical stimulation to enhance resolution of retinal prostheses. J Neurosci. 2014;34(14):4871-4881.

148. Twyford P, Fried S. The retinal response to sinusoidal electrical stimulation. IEEE Trans Neural Syst Rehabil Eng. 2016;24(4): 413-423.

149. Im M, Fried SI. Temporal properties of network-mediated responses to repetitive stimuli are dependent upon retinal ganglion cell type. $J$ Neural Eng. 2016;13(2):025002.

150. Stingl K, Bartz-Schmidt KU, Besch D, et al. Artificial vision with wirelessly powered subretinal electronic implant alpha-IMS. Proc Biol Sci. 2013;280(1757):20130077.

151. Chuang AT, Margo CE, Greenberg PB. Retinal implants: a systematic review. Br J Ophthalmol. 2014;98(7):852-856.

152. Stingl K, Bartz-Schmidt KU, Besch D, et al. Subretinal visual implant Alpha-IMS - Clinical trial interim report. Vis Res. 2015;111(Pt B):149160.

153. Zueva MV, Maghlakelidze N. The prospects of applying of technologies of nonlinear stimulation therapy to treat amblyopia. Glob J Intellect Dev Disabil. 2017;1(2):555556. 